\title{
Method-Method Pair Technique
}

\author{
Mohamed Imran Mohamed Ariff, Noreen Izza Arshad
}

\begin{abstract}
The CMB has always been a point of interest in most social science research. Recent works has highlighted the importance of evaluating CMB (Common Method Bias). The $C M B$ is concept method used by researchers to evaluate the reliability and validity of a certain research outcome. Furthermore, previous research states that the effect of $C M B$ can be a validity threat. The findings presented here employs the method-method pair technique in assessing the CMB. This technique is illustrated by observing the correlation of the transactive memory quality construct and team performance construct, obtained from a transactive memory systems research. Finally, in this paper, the implications of this technique for future research are highlighted and briefly discussed.
\end{abstract}

Keywords: CMB, component, method-method pair, team performance, transactive memory systems quality, validity threat.

\section{INTRODUCTION}

Research in the area of social science (e.g. Information Systems) often employs self-reporting data collected as empirical evidence (i.e. survey). In this type of research study, measurements of the constructs rely solely on the perceptual judgment of a single individual (e.g. employees in organizations). Common problems associated with selfreporting information collection is its threat to various types of method biases especially CMB (CMB). CMB is defined as the survey items that shows the methodology as compared to the measurement items [1]. The effect of CMB may include its effect on the factor loadings of the item scales thus effecting the correlation of measurement items and its constructs [3].

There have also been contradicting conclusions in the previous research about the effect of CMB. In [4] estimates that the CMB may pose a significant validity threat in the soundness of the published results. However, in [5] highlights that the effect of the CMB does not pose a serious validity threat in the soundness of the published results.

Previous literature has lighted both procedural and statistical methods in addressing the CMB issues [8]. These methods would be explained further in the following paragraphs. However, these proposed methods still are unable to address the validity of the measurement items used in the research thus affecting the overall results.

Although previous literature has shown that the proposed method in assessing CMB is the technique by [9], but the recent work from [10] has raised several key issues regarding the use of this method in assessing CMBes especially when using SmartPLS. Thus, in this study, the method proposed by [2] was chosen. This technique is also recommended by [11], especially when the research employs multiple methods in measuring its constructs.

Revised Manuscript Received on September 14, 2019.

Mohamed Imran Mohamed Ariff, Faculty of Computer and Mathematical Sciences, Universiti Teknologi MARA, Perak Branch, Tapah Campus, Malaysia.

Noreen Izza Arshad, Faculty of Science and Information Technology, Universiti Teknologi Petronas, Perak, Malaysia.
The remedial process for $\mathrm{CMB}$ are sometimes both procedural and statistical [1]. The methodology employed in this study includes testing the items in the survey questions to intense content adequacy assessment and a pilot test to improve instrument survey items thus providing a more consistent and unbiased scales. Likewise, the survey items were designed in specific method, that the independent and dependent variables were separated.

There has been several examining methods or technique proposed in evaluating the CMB, e.g. (1) Harman's post hoc one-factor test [1], (2) unmeasured latent method construct (ULMC) [9] and method-method pair technique. The following sections will explain more on these methods.

\section{CMB}

In a study that employs survey the measurement items employed solely relies on the perceptual judgment of a single individual (e.g. the employees in a manufacturing company). As a result, a $\mathrm{CMB}$ which is defined as variance that is resulted from the measurement method rather than to the constructs thus this can be effecting out overall outcome a study. It occurs in situations where information is obtained from the same respondent.

There are two major measurement or estimation errors reported when employing surveys: (1) measurement error due to the underlying construct itself and (2) due to the measurement artifacts. These measurement errors can contribute to inaccurate results thus leading to a wrong conclusion [2]. Another measurement error reported in previous literature is when common methods are chosen to measure similar constructs of interest. This situation creates biases when calculating the correlation between constructs of interest.

Previous literatures have widely acknowledged the extensive of CMBes. In [1] notes that there are both practical and arithmetical solutions to $\mathrm{CMB}$. The practical method in controlling CMB includes: (1) testing the questionnaire (measurement items of the survey) to rigorous review by peers and (2) using both a pre-test and pilot test. Both of these procedural methods have proven to improve the studies as the outcome results are more consistent based on unbiased measurement items. Another procedural approach is whereby, the questionnaire is designed so that criterion and predictor constructs are both separated and the rates are guaranteed anonymity for their participation in the particular survey.

The subsections below will highlight the statistical approach as one of the suggested remedies for controlling the CMB 


\section{METHOD-METHOD PAIR TECHNIQUE}

\section{A. UNITS Harman post hoc one-factor test [1]}

Using this test, if a significant amount of CMB is present, the exploratory factor analysis (EFA) of the analyzed data will consequence in a specific construct, which then accounts for the preponderance of the covariance in both DV and IV. The Harman's single-factor further highlights that no specific element accounted for the bulk of change in the items of interest, thus offering proof that this type CMB is not a serious worry. Thus, this test has been questioned as it does not cater for multiple factors in a research study, thus leading to the inability to detect the CMB.

\section{B. Unmeasured Latent Method Construct (ULMC)}

The ULMC states that if a substantial amount of CMB is present, then the exploratory factor analysis of the analyzed data will result in a single factor, which then accounts for the majority of the covariance in both DV and IV constructs.

Although the presence of CMB can be tested using the methods highlighted above, the methods has been criticized for its limitations. Thus, the most generally acceptable method or technique accepted by researchers is the multitrait-multimethod (MTMM) [1], [12]. MTMM was first proposed by [12] as means in assessing the validity of the measurement items in a research. In the MTMM method, the researcher is required to initialize different: (1) item of interest to operationalize each construct and (2) methods to measure each construct.

Although the MTMM method in assessing the CMB is well expected, there have been limitations in the MTMM especially when the survey primarily is investigated using Likert scale questionnaire measurement items. This is because the effect size reported in these studies cannot be portioned into the construct level correlations thus leading to a spurious correlation [15].

\section{ILLUSTRATION}

The research presented in this paper employs the use of the method-method pair technique towards forecasting effect of CMB by observing the correlations constructs in the research model by [16] (refer Fig. 1). This research model was chosen due to the complexity of the measurement items of interest and each construct uses a mixed of different measurement items, which were: (1) behaviorally anchored (BA) and (2) perceptually anchored (PA). Examples of these measurement items are as such below.

\section{A. Behaviorally Anchored (BA)}

Items refer to specific actions that people have carried out. Answers are on scales with behavioral anchors, such as "Never-More than once a day."

Example:

1) Our group performed together in a well-organized manner

2) I would rate the timeliness of the project's deliverables as:

\section{B. Perceptually Anchored (PA)}

Items encapsulates answers on "Agree-Disagree":

1) I would rate the quality of our project's deliverables as:
2) This project met its predefined scope

3) Our team has very few misunderstandings about what to do.

The research model by [16] is presented below

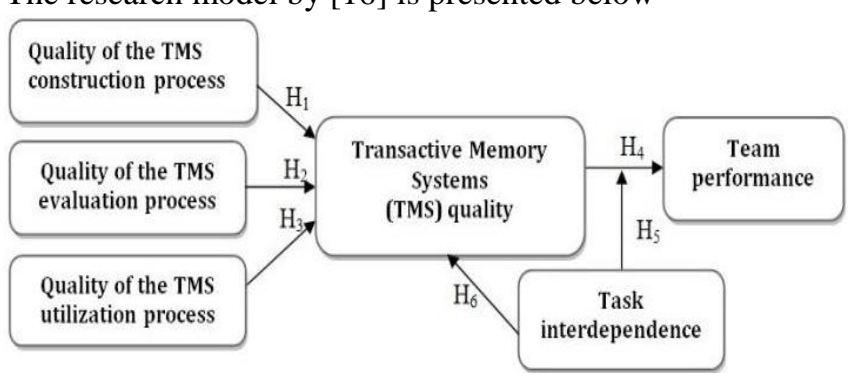

Fig. 1. Research model

Each of the hypotheses presented in the figure above is presented in Table I.

Table- I: Hypotheses

\begin{tabular}{|l|l|}
\hline $\mathrm{H}_{1}$ & $\begin{array}{l}\text { TMS construction process quality (CPQ) has a decisive } \\
\text { impact on the quality of TMS. }\end{array}$ \\
\hline $\mathrm{H}_{2}$ & $\begin{array}{l}\text { TMS evaluation process quality (EPQ) has a decisive } \\
\text { impact on the quality of TMS. }\end{array}$ \\
\hline $\mathrm{H}_{3}$ & $\begin{array}{l}\text { TMS utilization process quality (UPQ) has a decisive } \\
\text { impact on the quality of TMS. }\end{array}$ \\
\hline $\mathrm{H}_{4}$ & $\begin{array}{l}\text { Team accomplishment (TP) is strongly influenced team } \\
\text { performance. }\end{array}$ \\
\hline $\mathrm{H}_{5}$ & $\begin{array}{l}\text { The influence of TMS quality on team accomplishment } \\
\text { depends on task interdependence. }\end{array}$ \\
\hline $\mathrm{H}_{6}$ & $\begin{array}{l}\text { The association between task interdependence and team } \\
\text { execution is helped by the value of TMS. }\end{array}$ \\
\hline
\end{tabular}

Further explanation about the hypotheses presented above is beyond the scope of this research. However, further explanation above these hypotheses can be obtained from [16], [17].

An online survey was adopted in this research. The online survey in this research went live on the Survey Monkey ${ }^{\mathrm{TM}}$ server between mid-August 2012 until the end of September 2012. An email invitation was sent to the professionals highlighted by LinkedIn and identified through contacting the human resources managers in organizations.

LinkedIn is the world's largest professional online network. An advanced search was conducted by specifying the keyword 'virtual team'. After obtaining a listing of professionals involved in a 'virtual team', a further examination was conducted of their professional credentials. This was to double-check their involvement in virtual teams. Once this was done, an email invitation was sent to these professionals.

Data collection for this research was also conducted by contacting the human resources managers in organizations that handled virtual team projects. These organizations were provided with a sample of the survey so they could examine and understand the survey questions. Upon gaining the human resources managers' approvals, a web link containing the survey was forwarded to them with a 'request to participate' email. The human resources personnel then forwarded the web link to their co-workers who had been or who were currently working in a virtual team environment. 
Of the organizations contacted, those which agreed to participate in this research were in the high-technology ('high-tech') manufacturing industry. In this industry, primary work assignments ranged from short-term to longterm virtual team projects. These projects ranged from developing a research base, product development, sales and marketing to information technology consulting.

However, some of the organizations contacted had disallowed employee access to the Internet due to strict organizational security regulations. These organizations were handed hardcopies of the survey which the human resources personnel distributed to co-workers who had been or who were at present working in a virtual team atmosphere.

Participants in this exploration were mainly from Australia or Malaysia.

\section{METHOD-METHOD PAIR}

This technique evaluates the CMB based on the measurement methods employed in the research. The estimating of the effect of CMB is calculated through the observation of the correlation between the independent variable (IV) and dependent variable (DV) which is then ranked by their measurement methods.

\section{RESULTS AND DISCUSSION}

\section{A. Model 1}

Fig. 2 presents the outcomes of the PLS path assessment based on: (1) behavioral items for the TMS quality and (2) behaviorally anchored for team performance. Examples of the behaviorally anchored items for this study are as follows.

\section{TMS quality}

By the END of the project, when I needed specific knowledge that I did not possess, I could identify the team member who possessed that specific knowledge.

\section{Team performance}

The extent to which the project successfully met its original scope. Table II shows the correlation results from the research model presented in Fig. 2. The correlation between TMS condition and TP is shown diagonally-bolded. This indicates that there is a certain connection between TMS condition and TP. Further discussion on this will be provided at the discussion section of this research.

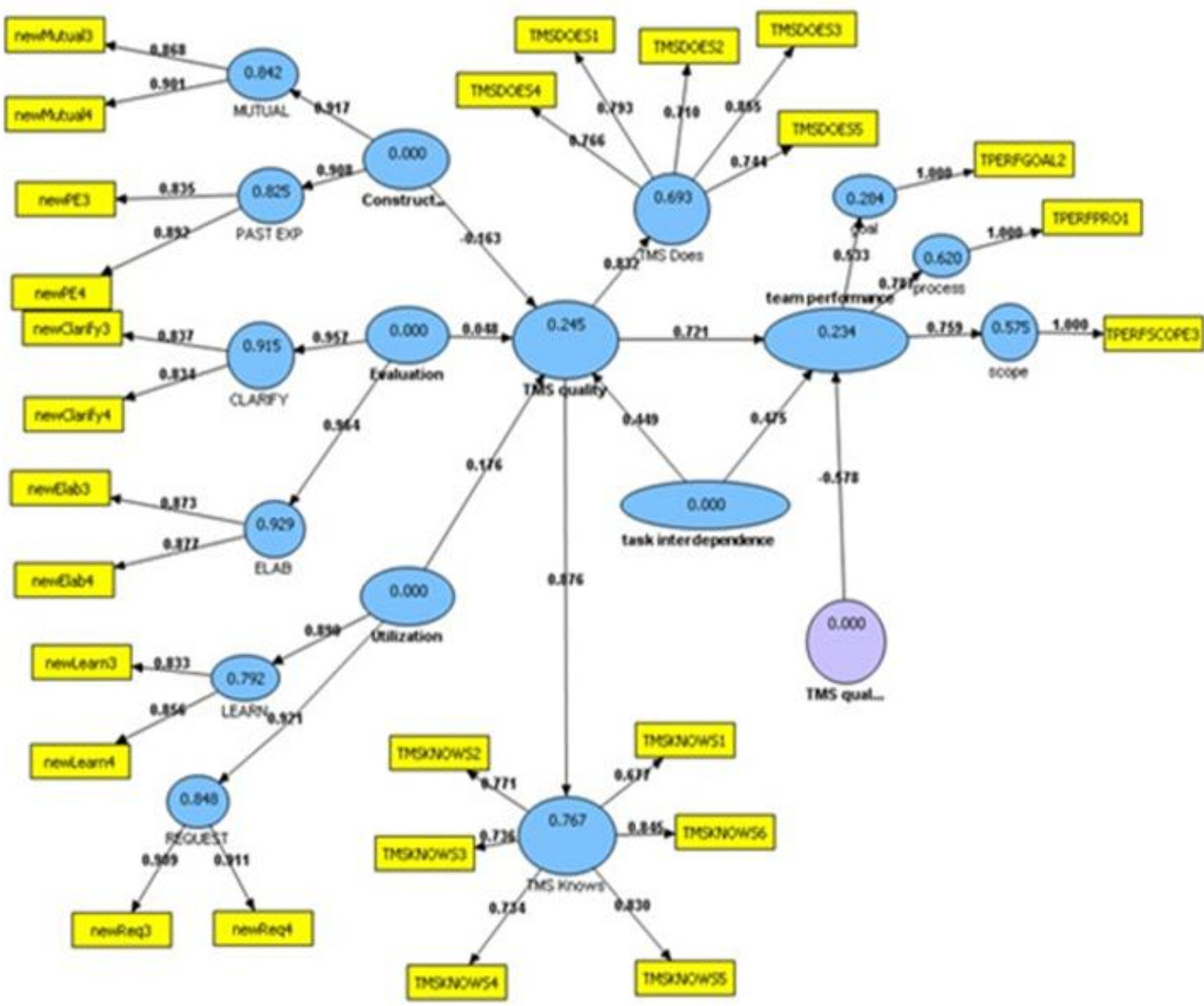

Fig. 2. Model 1 
Table- II: PLS path analysis

\begin{tabular}{|c|c|c|c|c|c|c|c|}
\hline & AVE & $\begin{array}{c}\text { Constructio } \\
\text { a }\end{array}$ & \begin{tabular}{|c|}
$\begin{array}{c}\text { Eraluatio } \\
\text { I }\end{array}$ \\
\end{tabular} & $\begin{array}{c}\text { Utilinatio } \\
\text { a }\end{array}$ & $\begin{array}{c}\text { TIS } \\
\text { quality }\end{array}$ & $\begin{array}{l}\text { Taskinter } \\
\text { dependence }\end{array}$ & Team performance \\
\hline Construction & 0.6351 & 0.997 & & & & & \\
\hline Evaluation & 0.6746 & 0.5693 & 0.821 & & & & \\
\hline Utilizstion & 0.6334 & 0.5697 & 0.6641 & 0.996 & & & \\
\hline TMS quality & 0.4353 & .0 .0212 & 0.0746 & 0.1681 & 0.660 & & \\
\hline $\begin{array}{l}\text { Taskinter } \\
\text { dependences }\end{array}$ & 0.5810 & 0.0315 & 0.0033 & 0.1177 & 0.4649 & 0.762 & \\
\hline Team performances & 0.4932 & 0.0058 & .0 .0598 & 0.0376 & 0.4654 & 0.3079 & 0.702 \\
\hline
\end{tabular}

Table- III: PLS path analysis

\begin{tabular}{|l|c|c|c|c|c|c|c|}
\hline & AIE & $\begin{array}{c}\text { Constructi } \\
\text { on }\end{array}$ & $\begin{array}{c}\text { Eraluatio } \\
\text { I }\end{array}$ & $\begin{array}{c}\text { Ctilizatio } \\
\text { ॥ }\end{array}$ & $\begin{array}{c}\text { TIS } \\
\text { quality }\end{array}$ & $\begin{array}{c}\text { Taskinter- } \\
\text { dependence }\end{array}$ & $\begin{array}{c}\text { Team } \\
\text { performance }\end{array}$ \\
\hline Construction & 0.6226 & 0.789 & & & & & \\
\hline Evaluation & 0.6009 & 0.3682 & 0.775 & & & & \\
\hline Utilization & 0.6704 & 0.1273 & 0.4203 & 0.819 & & & \\
\hline TMS quality & 0.4348 & 0.0614 & 0.1264 & 0.4285 & 0.059 & & \\
\hline $\begin{array}{l}\text { Taskinter- } \\
\text { dependence }\end{array}$ & 0.5799 & 0.1021 & 0.0066 & 0.2291 & 0.4737 & 0.702 & \\
\hline $\begin{array}{l}\text { Team } \\
\text { performance }\end{array}$ & 0.5095 & 0.1778 & 0.1020 & 0.2368 & 0.5193 & 0.3153 & 0.714 \\
\hline
\end{tabular}

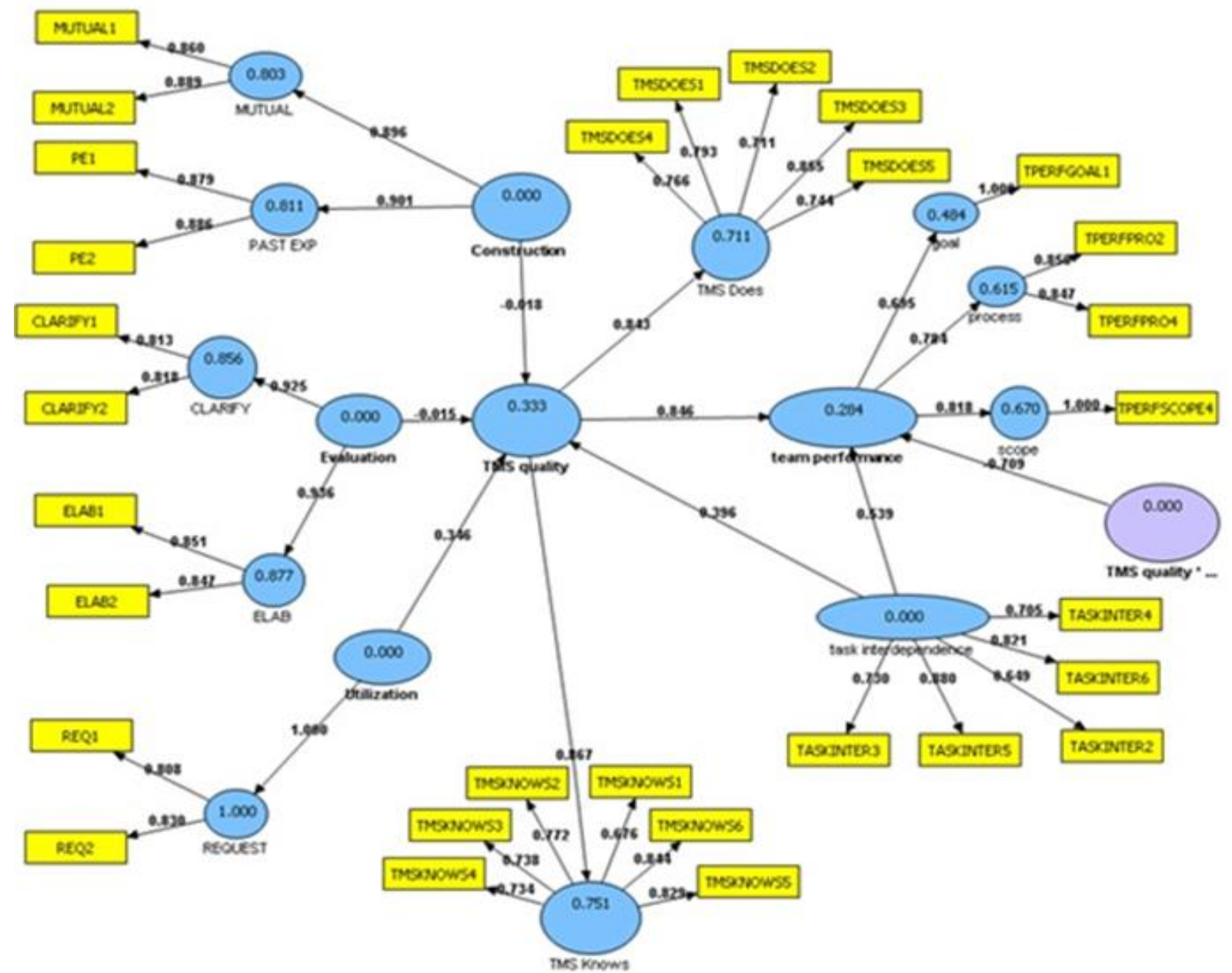

Fig. 3. Model 2

\section{CONCLUSION}

In this paper, method-method pair technique was used to access the $\mathrm{CMB}$ as suggested by [2]. Specifically, the evaluation of the $\mathrm{CMB}$ in this study examines the connection between the TMS value construct and the TP

\section{B. Model 2}

Fig. 3 represents the outcomes of the PLS path assessment based on the: (1) behavioral items for the TMS quality and (2) behaviorally anchored for team performance. Examples of the behaviorally anchored as well as perceptually anchored items for this study are as follows:

\section{TMS quality}

When other team members needed unexpected tasks on the project to be completed, they could identify the team member whose responsibility it was to perform that task.

\section{Team performance}

The project scope got extended during the course of the project. Table III shows the correlation results from the exploration model presented in Fig. 3. The correlation between TMS value and TP is shown diagonally-bolded. This indicates that there is a positive correlation between TMS value and TP.

construct. Results indicates, method-method pair technique is susceptible to $\mathrm{CMB}$ when measured by perceptually anchored (PA) items and is less susceptible when the DV is calculated using behavioral anchored items.

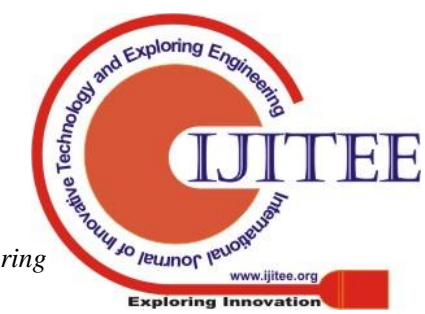


Based on this the findings indicates that the observed connection between the TMS value and TP correlations increases (from 0.4654 to 0.5193 ) thus indicating the correlation becomes more susceptible to CMB.

From the findings, it reveals that if this research were only to employ the measurement scale items base on model 2 (perceptually anchored dependent variable) it could lead to a strong validity threat. Thus, this study employs multiple measurement scale methods as recommended by [2] which can help significantly lower the CMBes.

\section{REFERENCES}

1. P. M. Podsakoff, S. B. MacKenzie, J. Y. Lee, and N. P. Podsakoff, "CMBes in behavioral research: A critical review of the literature and recommended remedies," Journal of Applied Psychology, 88(5), 2003, pp. 879903.

2. R. Sharma, P. Yetton, and J. Crawford, "Estimating the effects of common method variance: The method-method pair technique with an illustration from TAM research," MIS Quarterly, 33(3), 2009, pp. 473-490.

3. A. Burton-Jones, New perspectives on the system usage construct. PhD thesis, Atlanta: Georgia State University, 2005.

4. A. B. Woszczynski and M. E. Whitman, "The problem of common method variance in IS research," in The Handbook of Information Systems Research, M. Whitman and A. Woszczynski, Eds. Pennsylvania: IGI Global, 2004, pp. 66-77.

5. N. K. Malhotra, S. S. Kim, and A. Patil, "Common method variance in IS research: A comparison of alternative approaches and a reanalysis of past research," Management Science, 52(12), 2006, pp. 1865-1883.

6. S. A. Sivo, C. Saunders, Q. Chang, and J. J. Jiang, "How low should you go? Low response rates and the validity of inference in IS questionnaire research," Journal of the Association for Information Systems, 7(6), 2006, pp. 351-414.

7. H. Liang, N. Saraf, Q. Hu, and Y. Xue, "Assimilation of enterprise systems: The effect of institutional pressures and the mediating role of the management," MIS Quarterly, 31(1), 2007, pp. 59-87.

8. W. W. Chin, J. B. Thatcher, and R. T. Wright, Assessing CMB: Problems with the ULMC technique," MIS Quarterly, 36(3), 2012, pp. 1003-1019.

9. R. P. Bagozzi, "Measurement and meaning in information systems and organizational research: Methodological and philosophical foundations," MIS Quarterly, 35(2) 2011, pp. 261-292.

10. D. T. Campbell, and D. W. Fiske, "Convergent and discriminant validation by the multitrait-multimethod matrix," Psychological Bulletin, 56(2), 1959, pp. 81-105.

11. C. B. Jarvis, S. B. MacKenzie, and P. M. Podsakoff, "A critical review of construct indicators and measurement model misspecification in marketing and consumer research," Journal of Consumer Research, 30(2), 2003, pp. $199-218$.

12. S. B. MacKenzie, P. M. Podsakoff, and N. P. Podsakoff, "Construct Measurement and validation procedures in MIS and behavioral research: Integrating new and existing techniques," MIS Quarterly, 35(2), 2011, pp. 293-334.

13. M. I. M. Ariff, S. K. Milton, R. Bosua, and R. Sharma, "Transactive memory systems: Exploring task, expertise and people (TEP) unit formation in virtual teams: Conceptualization and scale measurement development,' Pacific Asia Conference on Information Systems, 2012, pp. 1-16.

\section{AUTHORS PROFILE}

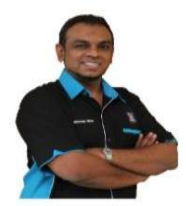

Smart PLS.
Mohamed Imran Mohamed Ariff received his Ph.D in Information Systems from the University of Melbourne, Australia in 2014. He is currently a Senior Lecturer in the Department of Computing Science at University Teknologi MARA (UiTM), Tapah Branch, Malaysia. His research interests include transactive memory systems (TMS), knowledge management, and

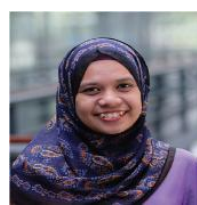

Noreen is an Associate Professor at the Universiti Teknologi PETRONAS in Malaysia. She is attached to the Department of Computer and Information Sciences and involves with teaching and research activities in the Information Systems cluster. Her primary research goals are directed toward understanding the use of living and quality of life technologies and how it could assist towards a better 